\title{
EFFECT OF SCALE INHIBITORS IN REVERSE OSMOSIS PROCESS
}

\author{
MOTOHIRO OKAZAKI AND SHOJI KIMURA \\ Institute of Industrial Science, The University of Tokyo, Tokyo 106
}

\begin{abstract}
Key Words: Membrane Separation, Crystallization, Scale Formation, Scale Inhibitor, Sodium
Hexametaphosphate, Reverse Osmosis
\end{abstract}

\section{Introduction}

The prevention of scale formation is very important for the practical application of the reverse osmosis process, where it is essential to maintain stable membrane characteristics in continuous long runs. Preventive methods of scale formation now used are softening by ion exchange resin, ${ }^{7)} \mathrm{pH}$ adjustment by the addition of acid, $^{5)}$ and addition of scale inhibitors. ${ }^{2,6)}$

We have been working on the rate of calcium sulfate dihydrate scale formation on the reverse osmosis membrane and have found that this phenomenon can be treated by the crystallization theory. ${ }^{3)}$ As a continuation of the above work, we tried to learn the effect of inhibitors on the rate of scale formation, because the addition of inhibitors is the most effective method for practical scale prevention, considering the operating cost, the simplicity of operation and the corrosion of apparatus. Materials used as inhibitor are sodium hexametaphosphate (SHMP), various organophosphates and so on. But their long-term inhibition effect is not clear, and there are various suggestions as to the mechanism of the inhibitor's action. ${ }^{1,5)}$

In this study, we performed long-term experiments using calcium sulfate dihydrate solution with addition of SHMP and commercially available organophosphates and investigated the mechanism of the inhibitor's action quantitatively.

\section{Theory}

Four basic equations for the estimation of membrane characteristics during scale formation are described as follows. ${ }^{4)}$ The concentration at the membrane surface, $C_{m}$, is given as

$$
\frac{C_{m}-C_{p}}{C_{b}-C_{p}}=\exp \left(\frac{J_{v}}{k}\right)
$$

The precipitation rate of scale per unit membrane

\footnotetext{
Received June 29, 1983. Correspondence concerning this article should be addressed to M. Okazaki.
}

surface area is expressed as

$$
\frac{d w}{d t}=k_{a} \cdot\left(C_{m}-C_{s}\right)^{2}
$$

where $k_{a}$ denotes the growth rate constant per unit membrane surface area. The permeate flux, $J_{v}$, can be determined by the flow resistance of the membrane and the scale layer. If a scale layer is formed, it gives resistance to the flow of water in series to that of membrane as

$$
J_{v}=\frac{\Delta p}{R_{m}+R_{s}}
$$

The value of $R_{s}$ is divided as follows:

$$
R_{s}=\alpha \cdot w, \quad w=W / A
$$

These simultaneous equations, containing four unknown quantities, $R_{s}, w, C_{m}, J_{v}$ were solved numerically.

\section{Experimental}

The experimental apparatus and procedure were essentially the same as in our previous study. ${ }^{3)}$ The inhibitors used in this study were sodium hexametaphosphate (SHMP) and a commercial scale inhibitor designated EL-2438. SHMP is the most popular inhibitor used in threshold treatment under relatively low-temperature conditions, and was supplied by Wako Pure Chemical Co. EL-2438 is mostly composed of organophosphate and was supplied by Calgon Corp. Both were added separately to the feed solution at a concentration from several to one hundred ppm at the beginning of the long-term run. The experimental conditions were as follows. The operating pressure was $5 \mathrm{MPa}$ and the flow rate was $3 \mathrm{l} / \mathrm{min}$ and all experiments were performed at $298 \mathrm{~K}$.

\section{Result and Discussion}

Figure 1 shows the results of long-term run with the addition of inhibitors, showing the changes of permeate flux as a function of time. In these results, the values of initial supersaturation degree at the mem- 


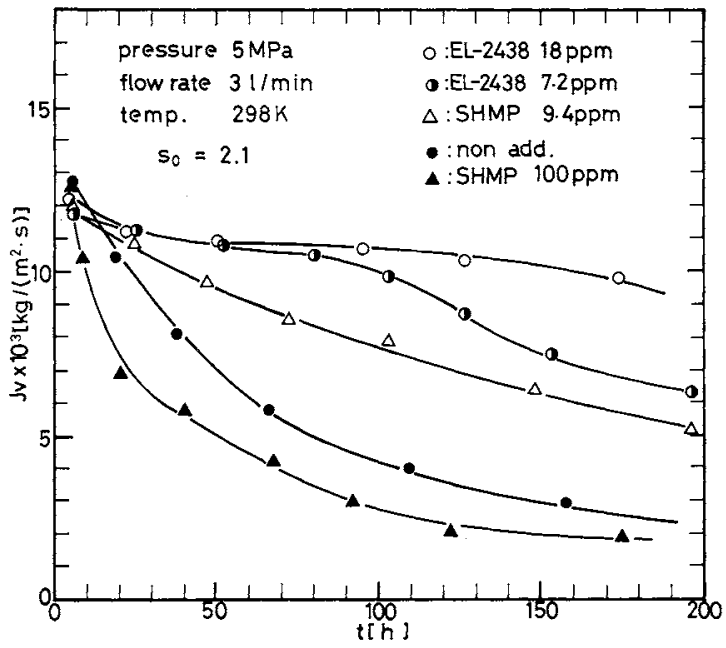

Fig. 1. Flux changes with time.

brane surface, $s_{0}$, were all the same. In the case of no addition, the permeate flux significantly decreased due to scale formation. But in the case of SHMP addition, decreasing rate of the permeate flux became lower and in the case of EL-2438 addition the rate became lower and the waiting period became longer.

In Fig. 2, the changes of supersaturation degree at the membrane surface, $s\left(=C_{m} / C_{s}\right)$, are illustrated as a function of time. The change of values corresponded to that of the permeate flux, and when the value of $s$ became almost unity, the permeate flux reached steady state. From these experimental results, we found that the mechanism of scale formation reported in our previous paper ${ }^{3)}$ was applicable also to the case of inhibitor addition.

As for the concentration of the inhibitor, for EL2438 addition the case of concentration at $18 \mathrm{ppm}$ was more effective than at $7.2 \mathrm{ppm}$. For SHMP addition, the change of concentration from 9.4 to $20 \mathrm{ppm}$ had very little influence on the inhibition effect. So the case of $20 \mathrm{ppm}$ addition was almost the same as that of $9.4 \mathrm{ppm}$. But on increasing the concentration to $100 \mathrm{ppm}$, the permeate flux greatly decreased compared to the case of no addition.

In the next place, in order to investigate the threshold treatment effect of inhibitors, the growth rate constant, $k_{a}$, was obtained using Eqs. (1), (2), (3) and (4). And the waiting period, $t_{w}$, which is the time from the beginning of supersaturation at the membrane surface to the start of the drop of permeate flux, was measured at each run. Their values are plotted against the value of $s_{0}$ in Figs. 3 and $\mathbf{4}$ and are compared with the case of no addition.

With regard to the growth rate constant, the value of $k_{a}$ became ten times smaller by addition of the inhibitor, because of the inhibition effect, and the value of $s_{0}$ was not dependent on the inhibitor addition. Thus it can be considered that the main

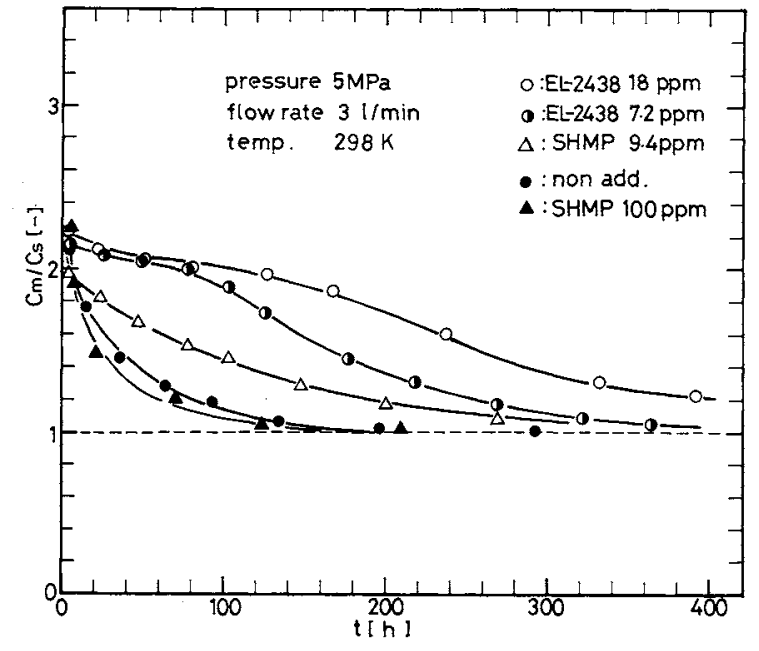

Fig. 2. Supersaturation degree changes with time.

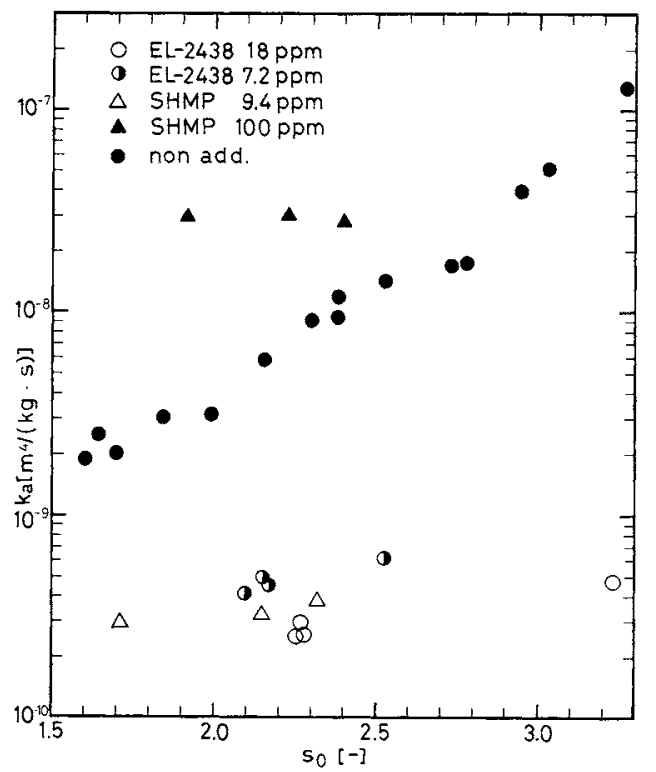

Fig. 3. Comparison of growth rate constant.

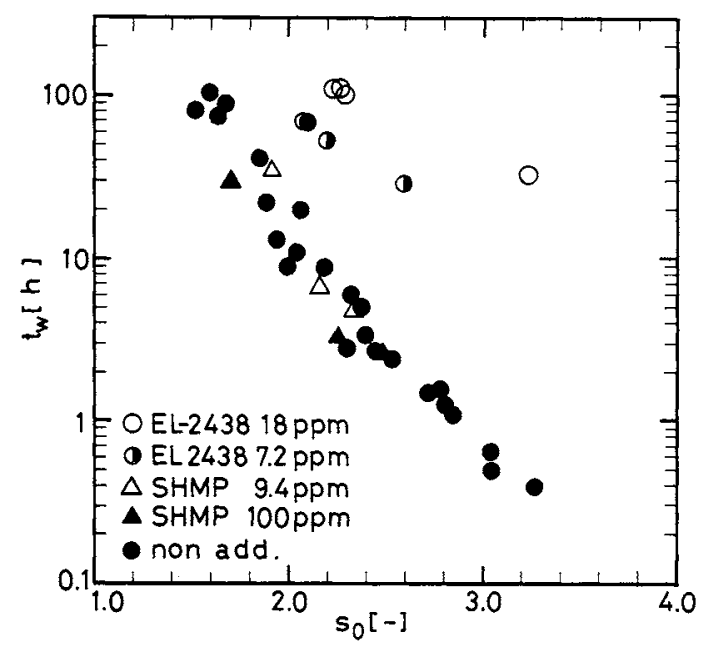

Fig. 4. Comparison of waiting period.

action of the inhibitor is to lower the rate of crystal growth. But at a concentration of $100 \mathrm{ppm}$ of SHMP, the apparent value of $k_{a}$ became larger than in the 
case of no addition and was constant irrespective of the value of $s_{0}$. In this case, the precipitated scale was not calcium sulfate dihydrate but SHMP. This is because SHMP dissociated in the solution and formed the polymeric species of the hydrophilic sol ${ }^{6)}$ and became the resistance to permeation.

Concerning the waiting period, in the case of SHMP addition the value of $t_{w}$ was almost the same as in the case of no addition, but in the case of EL2438 addition, the value of $t_{w}$ became larger. So it can be said that the scale prevention effect of the inhibitor is chiefly to lower the rate of crystal growth, ${ }^{1)}$ but it is also considered to prelong the waiting period in the case of organophosphate addition.

Consequently, we found that SHMP and the organophosphate inactivated the active growth site and lowered the rate of crystal growth, and the latter also prolonged the waiting period. Considering these results and the stability at high temperature and so on, ${ }^{1)}$ organophosphate is thought to be more effective than SHMP as an inhibitor.

\section{Acknowledgment}

The authors are grateful to Calgon Corp., Ltd. for supplying EL2438.

Nomenclature

$\begin{array}{llr}A & =\text { membrane surface area } & {\left[\mathrm{m}^{2}\right]} \\ C & =\text { concentration of solute } & {\left[\mathrm{kg} / \mathrm{m}^{3}\right]} \\ J_{v} & =\text { volume flux } & {\left[\mathrm{kg} /\left(\mathrm{m}^{2} \cdot \mathrm{s}\right)\right]} \\ k & =\text { mass transfer coefficient } & {[\mathrm{m} / \mathrm{s}]} \\ k_{a} & =\text { growth rate constant per unit membrane surface }\end{array}$

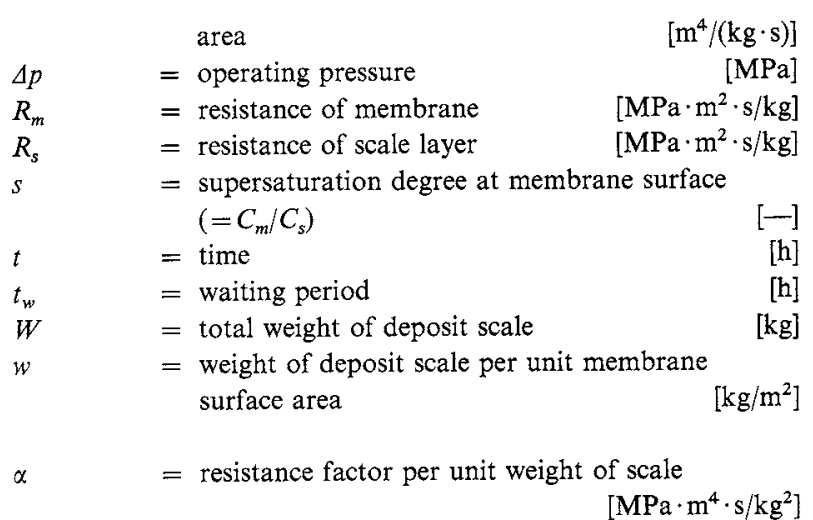

〈Subscripts〉

$\begin{array}{ll}b & =\text { bulk solution } \\ m & =\text { membrane } \\ p & =\text { product } \\ s & =\text { saturation } \\ 0 & =\text { initial value }(t=0)\end{array}$

\section{Literature Cited}

1) Cowan, J. C. and D. J. Weintritt: "Water-Formed Scale Deposits," Gulf Publishing Co., p. 250 (1976).

2) Doelle, R. R. and J. R. Smith: Desalination, 32, 113 (1980).

3) Okazaki, M. and S. Kimura: J. Chem. Eng. Japan, in press.

4) Sugita, S.: Bull. Soc. Sea Water Sci. Japan, 27, 106 (1973).

5) Tidball, R. A., D. Kuiper, P. H. Lange and R. Kadaj: Desalination, 29, 319 (1979).

6) Tsuge, H., Y. Sugino, M. Takeda and T. Matsumoto: 9th Tech. Proc.-Annu. Conf. Int. Trade Fair Natl. Water Supply Improv. Assoc., Vol. 1, Paper 18 (1981).

7) Wilf, M., M. Konstantin and A. Chencinsky: Desalination, 34, $189(1980)$.

\section{SIZES OF DROPLETS PRODUCED IN THE JETTING REGIME AT SINGLE ORIFICES}

TOSHIRO MIYAHARA AND TERUO TAKAHASHI

Department of Industrial Chemistry, Okayama University, Okayama 700

Key Words: Distillation, Fluid Mechanics, Spray, Jetting, Droplet

The use of high gas velocities and perforated plates having relatively large free areas leads to the operation of the spray regime. The behavior of droplets in the spray regime differs from that in the more commonly used froth regime in industrial operations. ${ }^{2)}$ Most previous studies of droplet sizes on perforated

\footnotetext{
Received July 28, 1983. Correspondence concerning this article should be addressed to T. Miyahara.
}

plates have been confined to the froth regime. ${ }^{1,8)}$ Pinczewski et al. $\left.{ }^{6}\right)$ have shown detailed measurements of droplet size in the spray regime in the air-water system on a series of industrial-scale perforated plates having hole diameters of $6.3-19.1 \mathrm{~mm}$ and free areas of $5-16 \%$ and reported that the size distributions were found to be well correlated by an upper limit logarithmic normal probability distribution. Hence, the 